\title{
2006-3: ENHANCING INTERDISCIPLINARY INTERACTIONS IN THE COLLEGE OF ENGINEERING AND NATURAL SCIENCES
}

\author{
Bryan Tapp, University of Tulsa \\ Bryan Tapp is an Associate Professor and Chair of the Department of Geosciences at The \\ University of Tulsa. His interests include strain measure, deformation mechanisms in rock, and \\ the application of numerical methods in modeling rock deformation.
}

\section{Donna Farrior, University of Tulsa}

Donna Farrior is an Applied Assistant Professor of Mathematics and Associate Chair of Mathematics in the Department of Mathematical and Computer Sciences at The University of Tulsa.

\section{Jerry McCoy, University of Tulsa}

Jerome McCoy is an Applied Assistant Professor in the Department of Physics and Engineering Physics at The University of Tulsa.

\section{Leslie Keiser, University of Tulsa}

Leslie Keiser is a graduate student in the School of Education at The University of Tulsa.

\section{Peter LoPresti, University of Tulsa}

Peter LoPresti is an Associate Professor of Electrical Engineering at The University of Tulsa. His interests include the support of undergraduate participation in research, optical networks, fiber optic sensors, sensor networks, and artificial vision. He is a member of both IEEE and ASEE.

\section{Shirley Pomeranz, University of Tulsa}

Shirley Pomeranz is an Associate Professor of Mathematics in the Department of Mathematical and Computer Sciences at The University of Tulsa. She is the 2005-2007 ASEE PIC III Chair and is a member of the Editorial Advisory Board for The International Journal of Engineering Education. Her interests include support of women in mathematics and research involving the boundary element method.

\section{William Hamill, University of Tulsa}

William Hamill is a Visiting Assistant Professor of Mathematical Sciences at The University of Tulsa.

\section{William Potter, University of Tulsa}

William Potter is a Professor of Chemistry in the Department of Chemistry and Biochemistry at The University of Tulsa. 


\section{Enhancing Interdisciplinary Interactions in the College of Engineering and Natural Sciences}

\section{Introduction and Project Goals}

A team of faculty members in the College of Engineering and Natural Sciences at The University of Tulsa (TU) began work in July 2004 on a National Science Foundation (NSF)-funded Course, Curriculum, and Laboratory Improvement (CCLI) Project (Proposal \# 0410653). This two-year project was based on the use of Interdisciplinary Lively Application Projects (ILAPs) ${ }^{1}$ as a vehicle for strengthening connections among science, engineering, and mathematics departments $^{2}$. The concept of ILAPs originated from a consortium of 12 schools led by the United States Military Academy (USMA) with an NSF funded project, Project INTERMATH ${ }^{3}$. ILAPs are interdisciplinary group problem-solving projects designed for undergraduates, cowritten by mathematics faculty and science/technology/engineering faculty. These small group projects are designed to foster student interest by being lively. Being "lively" means that students are actively involved in and outside of class with project problem solving and/or hands-on activities. ILAPs can motivate students to understand the connections between mathematical tools/concepts and applications within the broader science and engineering fields. With these projects STEM students see real-world applications of mathematics in science and engineering.

One of the main goals of the project was to produce assessment data on the effectiveness of ILAPs in learning. There is much anecdotal evidence to support claims that students benefit in many ways from ILAPs. For example, ILAPs demonstrate how mathematics is used in partner disciplines ${ }^{4}$, give students experience in working and communicating as part of an interdisciplinary team, provide practical experience in the use of technology, etc. However, formal assessments on the pedagogical effectiveness of ILAPs and similar projects are only just beginning to appear in the literature ${ }^{5}$. This project makes an initial contribution to such analyses.

Another focus of the project was the enhancement of interactions between mathematics faculty and faculty in science/engineering disciplines. Although mathematical concepts and principles remain the same, terminology and notation differ among the disciplines. In order for faculty to be able to inform students of these connections, faculty must be aware of terminology and notation beyond their own disciplines. A strong cooperative environment allows faculty to share ideas and concerns regarding instruction, and identify needs for improving student preparation. Therefore, strengthening the connections among faculty, as well as the courses they teach and the technology that they use, can be beneficial to both students and faculty in providing a more cohesive instructional environment. A previous paper summarizing this project's results after its first year appeared in the 2005 ASEE Conference Proceedings ${ }^{6}$. We report on this project, now, two years after its inception. Additional information, ILAPs, and supporting items are available for download at the project web site, http://www.ilaps.utulsa.edu/.

\section{Project Design}

The project was designed to introduce ILAPs into the mathematics curriculum by phasing in their implementation over several semesters. In the first academic year (first two semesters), 
ILAPs from various engineering and science disciplines were introduced into the foundation calculus courses (Calculus I and II), with two ILAPs (projects) per semester per class. In each course, one section of the course was assigned a traditional calculus project instead of the ILAP in order to provide a control group for evaluation and assessment. The traditional projects were similar to the projects in the course text ${ }^{7}$ that were not interdisciplinary, applied, or hands-on. Assessment was provided by an independent evaluator. Using the results and recommendations from the first year, ILAPs were introduced into Calculus III in the second year, and the ILAPs for Calculus I and II were refined and re-evaluated. In addition, the ILAPs formed a basis for class projects in various science and engineering courses to reinforce the connection between engineering concepts and the underlying mathematics. A national project advisory board presented recommendations.

In addition to the ILAP work, two hands-on computer workshops and a faculty colloquium were held each semester to help strengthen the interaction between STEM faculties. The computer workshops were designed to provide basic instruction in the use of computational software packages that are in common use in all disciplines, and they were open to faculty and students. The workshop focus was on MATLAB and Mathematica and the practical use of these packages for problem solving. The faculty colloquia were open forums for faculty discussion of ideas, problems, and needs regarding ILAPs and mathematics, engineering, and related interdisciplinary instruction in general.

\section{ILAP/Non-ILAP Schedule}

This two-year project was begun in late summer, 2004 and concluded in the summer of 2006. Teams consisting of two to four students worked on each project for two weeks. We also had control classes of students who did projects that were not interdisciplinary and not hands-on. We have team-taught the following ILAPS (see Figure 1).

\section{Fall 2004 - Calculus I ILAPs}

Electrical Engineering-Math ILAP: Designing an electric car - RC circuits and exponential growth/decay.

Chemistry-Math ILAP: Chemical kinetics - decay of phenolphthalein in the presence of sodium hydroxide and exponential decay.

\section{Spring 2005 - Calculus II ILAPs}

Physics-Math ILAP: Planck's law for blackbody radiation - A Mathematica project. Mechanical Engineering-Math ILAP: Beam deflection using real-time sensors.

\section{Fall 2005 - Calculus I ILAPs}

Electrical Engineering-Math ILAP: An electric car - RC circuits and exponential growth/decay revisited.

Physics-Math ILAP: Introduction to the special theory of relativity using Mathematica: Galilean versus Lorentz transformations. 


\section{Fall 2005 - Calculus II ILAP}

Chemistry-Math ILAP: Saving a drug-poisoning victim 8 - exponential decay and related differential equations.

\section{Fall 2005 - Calculus III ILAP}

Geosciences-Math ILAP: Strain tensor, displacement vector, and deformation matrices; vector and tensor calculus.

\section{Spring 2006 - Calculus II ILAP}

Chemical Engineering-Math ILAP: Wastewater treatment facilities - Curve fitting and integration ${ }^{3}$.

\section{Spring 2006 - Calculus III ILAP}

Physics-Math ILAP: Physics applications of surface integrals.

\begin{tabular}{|c|c|c|c|c|}
\hline Semester & Fall Year 1 & Spring Year 1 & Fall Year 1 & Spring Year 2 \\
\hline $\begin{array}{c}\text { MATH } \\
2014 \\
\text { Calculus I }\end{array}$ & $\begin{array}{c}\text { Electrical } \\
\text { Engineering-Math } \\
\text { ILAP } \\
\text { Chemistry-Math } \\
\text { ILAP } \\
\end{array}$ & & $\begin{array}{l}\text { Electrical Engineering- } \\
\text { Math ILAP } \\
\text { Physics-Math ILAP }\end{array}$ & \\
\hline $\begin{array}{c}\text { MATH } \\
2024 \\
\text { Calculus II }\end{array}$ & & $\begin{array}{l}\text { Physics-Math } \\
\text { ILAP } \\
\\
\text { Mechanical } \\
\text { Engineering - } \\
\text { Math ILAP } \\
\end{array}$ & Chemistry-Math ILAP & $\begin{array}{c}\text { Chemical } \\
\text { Engineering-Math } \\
\text { ILAP }\end{array}$ \\
\hline $\begin{array}{l}\text { MATH } \\
2073 \\
\text { Calculus } \\
\text { III }\end{array}$ & & & $\begin{array}{c}\text { Geosciences-Math } \\
\text { ILAP }\end{array}$ & Physics-Math ILAP \\
\hline
\end{tabular}

Figure 1. ILAP Schedule

This was our first attempt at introducing ILAPs into our courses, although we had used group projects in the calculus courses prior to this. We had not previously used interdisciplinary or hands-on features of projects. Our ILAPs have at least one of these features. We constructed our ILAPs and non-ILAPs keeping in mind students' comments from previous projects. We gave students information packets containing the following (which are posted at our web site): project description and assignment, grading policy and related information, technical report format and writing guide, sample report, information on working effectively in small groups, first group meeting form, and small group peer evaluation forms.

\section{Project Results}

Douglas Grouws, Mathematics Education, University of Missouri, was the external independent evaluator in charge of assessments. Leslie Keiser, a TU graduate student, assisted him with the 
assessment process. The following data apply for the results summarized in Tables 2 and 3 . There were 75 ILAP students and 27 non-ILAP students in the spring 2005 Calculus II classes. In the ILAP sections of Calculus II, $81 \%$ of the students were male and $19 \%$ were female. In the non-ILAP sections, $71 \%$ of the students were male and $29 \%$ were female.

\section{Student Questionnaires}

Students had about two weeks to work on each project. After each project was submitted, students completed questionnaires. The results from the student questionnaires for the spring 2005, Calculus II, Physics-Math ILAP are shown in Figure 2. The results from the student questionnaires for the spring 2005, Calculus II, Mechanical Engineering-Math ILAP are shown in Figure 3.

\section{Figure 2. Questions 1 - 8 \\ Spring 2005 - Calculus II - Physics-Math (Planck's Law) ILAP \\ Questionnaire Results - Median for ILAP vs. Non-ILAP Students (Response Rate 80\%) \\ (ILAP results are highlighted yellow. Non-ILAP results are highlighted green. If both ILAP and non-ILAP results are the same, then the result is highlighted red.)}

Question 1: How much time did you spend on the project? Response: ILAP students spent an average of 10 hours on the project. Non-ILAP students spent an average of 7 hours.

Question 2: How many group meetings did you have? Response: ILAP students had an average of 5 meetings versus non-ILAP students who had an average of 3 meetings.

Note: See Question 4 - Generally, four-person groups were used.

\begin{tabular}{|c|c|c|c|c|c|c|}
\hline Question & $\begin{array}{l}\text { Strongly } \\
\text { Disagree }\end{array}$ & Disagree & $\begin{array}{c}\text { Slightly } \\
\text { Disagree }\end{array}$ & $\begin{array}{c}\text { Slightly } \\
\text { Agree }\end{array}$ & Agree & $\begin{array}{c}\text { Strongly } \\
\text { Agree }\end{array}$ \\
\hline $\begin{array}{l}\text { 3. The class introduction helped me understand } \\
\text { the project better than if I had just read } \\
\text { through the project description. }\end{array}$ & 1 & 2 & 3 & 4 & 5 & 6 \\
\hline $\begin{array}{l}\text { 4. I was satisfied with how my group worked } \\
\text { together on this project. }\end{array}$ & 1 & 2 & 3 & 4 & 5 & 6 \\
\hline $\begin{array}{l}\text { 5. This project helped me make a connection } \\
\text { between calculus and the real world. }\end{array}$ & 1 & 2 & 3 & 4 & 5 & 6 \\
\hline $\begin{array}{l}\text { 6. By completing this project, I gained a better } \\
\text { understanding of improper integrals and } \\
\text { their uses. }\end{array}$ & 1 & 2 & 3 & 4 & 5 & 6 \\
\hline 7. I found this project interesting. & 1 & 2 & 3 & 4 & 5 & 6 \\
\hline $\begin{array}{l}\text { 8. If I had to choose between a project with a } \\
\text { hands-on application and a project that } \\
\text { focused strictly on the mathematics, I would } \\
\text { choose the one with the hands-on } \\
\text { application. }\end{array}$ & 1 & 2 & 3 & 4 & 5 & 6 \\
\hline
\end{tabular}


Figure 3. Questions 1 - 8

Spring 2005 - Calculus II -Mechanical Engineering-Math (Beam Deflection) ILAP

Questionnaire Results - Median for ILAP vs. Non-ILAP Students (Response Rate 53\%)

(ILAP results are highlighted yellow. Non-ILAP results are highlighted green. If both ILAP and non-ILAP results are the same, then the result is highlighted red.)

Question 1: How much time did you spend on the project? Response: ILAP students spent an average of 4 hours on the project. Non-ILAP students spent an average of 5 hours.

Question 2: How many group meetings did you have? Response: ILAP students had an average of 3 meetings versus non-ILAP students who had an average of 3 meetings.

Notes: See Question 4 - Generally, two-person groups were used.

See Question 6 - Students in non-ILAP class requested and received a brief discussion of the mechanical engineering interpretation on their project.

\begin{tabular}{|c|c|c|c|c|c|c|}
\hline Question & $\begin{array}{l}\text { Strongly } \\
\text { Dis agree }\end{array}$ & Disagree & $\begin{array}{c}\text { Slightly } \\
\text { Dis agree }\end{array}$ & $\begin{array}{c}\text { Slightly } \\
\text { Agree }\end{array}$ & Agree & $\begin{array}{c}\begin{array}{c}\text { Strongly } \\
\text { Agree }\end{array} \\
\end{array}$ \\
\hline $\begin{array}{l}\text { 3. The class introduction helped me understand the } \\
\text { project better than if I had just read through the } \\
\text { project description. } \\
\text { 4. I was satisfied with how my group worked } \\
\text { together on this project. }\end{array}$ & 1 & 2 & 3 & 4 & 5 & 6 \\
\hline $\begin{array}{l}\text { 5. This project helped me make a connection } \\
\text { between calculus and the real world. } \\
6 \text {. By completing this project, I gained a better } \\
\text { understanding of beam deflection. }\end{array}$ & 1 & 2 & 3 & $\begin{array}{l}4 \\
4\end{array}$ & 5 & 6 \\
\hline 7. I found this project interesting. & 1 & 2 & 3 & 4 & 5 & 6 \\
\hline $\begin{array}{l}\text { 8. If I had to choose between a project with a } \\
\text { hands-on application and a project that focused } \\
\text { strictly on the mathematics, I would choose the one } \\
\text { with the hands-on application. }\end{array}$ & 1 & 2 & 3 & 4 & 5 & 6 \\
\hline
\end{tabular}

\section{Conceptions of Mathematics Inventory}

On the first day of classes, the fall 2004 Calculus I students were given a Conceptions of Mathematics Inventory (CMI). This inventory was also given again at the end of spring 2005 to the Calculus II students. The results from the 48 students who were in both classes are compared in Figure 4. Students answered on a Likert scale from 1 to 6 . A response of 1 is associated with the description given in the left column of the table in Figure 4. A response of 6 is associated with the description given in the right column of the table in Figure 4. Values "in-between" are associated with descriptions "in-between". 


\section{Figure 4.}

Comparison of Conceptions of Mathematics Inventory (CMI) Results. CMI given at start of fall 2004 Calculus I and at end of spring 2005 Calculus II. Data collected for 48 students who took both fall 2004 and spring 2005 CMI . AVERAGE VALUES.

\begin{tabular}{|c|c|}
\hline 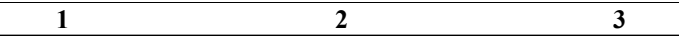 & 5 \\
\hline \multicolumn{2}{|l|}{ I. Natureof Mathematical Knowledge } \\
\hline 1. $\frac{\text { Composition of M athematical }}{\text { Know ledge }}$ & F a 11: $3.87 \quad$ S p ring: 3.72 \\
\hline $\begin{array}{c}\text { K now ledge as facts, formulas, and } \\
\text { algorithms }\end{array}$ & $\begin{array}{c}\text { K now ledge as concepts, principles, and } \\
\text { generalizations }\end{array}$ \\
\hline 2. Structure of M athematical Know ledge & \multirow{2}{*}{$\begin{array}{cc}\text { F all: } 4.47 & \text { Spring: } 4.47 \\
\text { athematics as a coherent system }\end{array}$} \\
\hline $\begin{array}{c}\text { M athem atics as a collection of isolated } \\
\text { pieces }\end{array}$ & \\
\hline 3. Status of M athematical Know ledge & \multirow{2}{*}{$\begin{array}{l}\text { Fall: } 3.66 \\
\text { M a the } m \text { atics as a dynamic field }\end{array}$} \\
\hline M athematics as a static entity & \\
\hline \multicolumn{2}{|l|}{ II. Nature of Mathematical Activity } \\
\hline 4. Doing $\mathrm{M}$ athem atics & \multirow{2}{*}{$\begin{array}{l}\text { F a ll: } 4.68 \\
\text { M athem atics as } \\
\end{array}$} \\
\hline M athematics as results & \\
\hline 5. Validating Ideas in $M$ athematics & Spring: 4.08 \\
\hline Outside authority & $\begin{array}{c}\text { Fall: } 4.19 \\
\text { Logicalthought }\end{array}$ \\
\hline \multicolumn{2}{|l|}{ III. Learning Mathematics } \\
\hline & \multirow{2}{*}{ Spring: 4.08} \\
\hline $\begin{array}{l}\text { 6. Learning as memorizing intact } \\
\text { know ledge }\end{array}$ & \\
\hline \multicolumn{2}{|l|}{ IV. Usefulness of $M$ athematics } \\
\hline & Spring: 4.71 \\
\hline $\begin{array}{l}\text { 7. M athematics as a school subject with } \\
\text { little value in everyday life or future work }\end{array}$ & M athematics as a usefulendeavor \\
\hline
\end{tabular}

For example, with respect to Dimension 1: The Nature of Mathematical Knowledge Composition of Mathematical Knowledge, a response of 1 indicates that a student feels that mathematical knowledge consists of knowing facts, formulas, and algorithms. On the other extreme, a response of 6 indicates that a student interprets mathematical knowledge as concepts, principles, and generalizations. A mean value was calculated using the 48 student responses for each of the 7 dimensions. The dimensions consist of Dimension 1: Composition of Mathematical Knowledge; Dimension 2: Structure of Mathematical Knowledge; Dimension 3: Status of Mathematical Knowledge; Dimension 4: Doing Mathematics; Dimension 5: Validating Ideas in Mathematics; Dimension 6: Learning Mathematics; and Dimension 7: Usefulness of Mathematics.

Comparing the fall 2004 data with the spring 2005 data, as presented in Figure 4, it appears that our calculus students are not strongly influenced in the positive directions that we would like by taking our Calculus I and Calculus II courses. Here, for each of the 7 conceptions, taking the value of 6 as "desirable" and the value of 1 as "undesirable", the average values generally dropped slightly over the two year period. According to these data, rather surprisingly, our students' answers suggested that mathematical sophistication/maturity is reduced by taking calculus courses! It is possible that these results merely indicate a more realistic, rather than 
idealistic, understanding of mathematics by the students. The largest drop was observed for the "usefulness of mathematics" conception, which, unfortunately, is a primary goal within mathematics education.

In this study, we were looking for hypotheses, i.e., trends to be investigated further in larger studies. This overall project was itself not a research study; the research on assessment of the pedagogical effectiveness of ILAPs was but one component of the project. Our preliminary results indicate that introducing ILAPs into the first two semesters of the calculus sequence may not have the desired effect of enhancing students' learning. We have not seen significant differences between the data collected from ILAP students versus the data from non-ILAP students. Given the fact the syllabus for the first semesters of calculus is packed with topics, ILAPs introduced into the more advanced courses may serve students better than ILAPs in the introductory calculus courses (at institutions similar to ours).

\section{National Advisory Board and Recommendations}

The project had a national advisory board that contributed input and had one on-site meeting at TU in March 2005. The advisory board members were as follows: Dr. Douglas Grouws, Professor, Mathematics Education, University of Missouri (project evaluator); Col. Joe Myers, Associate Professor, Department of Mathematical Sciences, USMA; Dr. John Scharf, Professor and Chair, Department of Mathematics, Engineering and Computer Science, Carroll College, Helena, MT; Dr. Anton Pintar, Professor Emeritus of Chemical Engineering, Michigan Technological University; Dr. Robert Howard, Professor, Department of Chemistry and Biochemistry, TU; and Dr. Robert Strattan, Professor Emeritus of Electrical Engineering, TU.

Some of the suggestions from this advisory board were as follows.

\section{Project Mechanics:}

- Consider reusing previous ILAPs from TU and elsewhere (adapt and implement), rather than developing everything from scratch.

- Consider having a mix of data-based and analytic (non-data-based) ILAPs.

- Give students a selection of ILAP topics.

-Devote more class time to doing group work

-Provide more structure, and don't hesitate to step students through some requirements with respect to the ILAPs for freshmen (consider small, frequent, straightforward questions). More open-ended, less structured ILAPs can be used for higher-level classes.

\section{Project Management:}

-Communicate better to students the value of ILAPs in curriculum, especially with respect to preparing students to function as part of interdisciplinary teams that have to communicate results to others.

-Explain clearly to students that this is a regular part of the course, and that students will do either an ILAP or a non-interdisciplinary, non-applied project.

-Encourage the administration to advertise and support the project.

-Prepare a solid foundation in order to sustain the project. Make clear to others why ILAPs are indispensable. For example, such projects can be used to enhance Accreditation Board for 
Engineering and Technology (ABET) and/or North Central Association (NCA) Commission on Accreditation and School Improvement assessments, support interdisciplinary faculty collaboration, and support student learning and integration of curricula.

- Continue progress in coordinating curricula using mathematics to build coherence, and build infrastructure to sustain the progress that has been made.

General Ideas for Enhancing the Project:

-Use some data from departmental labs rather than generating new data for each ILAP. In addition to being efficient, this extends science and engineering labs to other courses in a continuous and interdisciplinary fashion.

-Consider one ILAP per semester rather than two, especially for first semester freshmen.

- Consider ILAP presentations or poster sessions as a change of pace and as a method of developing different modes of communication.

-Strive for more visibility of current-semester student reports.

- Consider extending the idea of ILAPs to high school students.

\section{Possible Pitfalls and Difficulties in Successfully Implementing ILAPs}

In the process of generating ILAPs and implementing them in a classroom setting, we encountered a number of difficulties that hindered the success of the project. These difficulties are described below in the hope that others who are interested in using ILAPs in their curricula may avoid them through awareness of and planning for potential problems.

\section{Prepare Students for the Issue of Experimental Error}

This problem was exposed during the very first ILAP that was implemented. For the experimental component of the Electrical Engineering ILAP on RC time constants, there was no allowance made or guidance given for the presence of experimental error. On lab day, the students quickly discovered that the accuracy of their calculations strongly depended on which electric motor had been installed in their car, with some motors running over 20 seconds and others running under 10 seconds for the same charge on the capacitor supplying energy to the motor. Many of the students were confused by this turn of events, as they expected the calculations and data to be reasonably close. The instructors' attempts to alleviate the problem on the fly only confused the students further, negatively impacting the effectiveness of the exercise.

When the ILAP was rewritten for the fall semester of 2005, the instructions for the experimental portion of the ILAP explicitly described both the possibility for experimental error and the probable causes, such as component tolerances, accuracy of the timing equipment (usually just a watch), and, of course, variability in motor operation. The students were required to average their results over several trials and to calculate the observed percent error. If the observed error fell within defined "acceptable limits", the experiment was a success. While the motor performance still varied in the fall 2005 session, this bothered the students less, and initial reactions, based on in-class surveying, were far more positive. 
There are many factors that contribute to a student's attitude in the classroom, including student stress (lack of sleep, etc.), classroom conditions (noise level, temperature, etc.), and a professor's attitudes and abilities. These factors are generally ignored for data collection purposes because of the complications involved. However, for this project, it is very important to emphasize the impact of professor attitudes. Some professors had a general apathy towards the use of ILAPs in their courses. Some professors had untimely amounts of work to do for each ILAP, which contributed to poor attitudes toward the project. Others had their own classroom schedules which didn't include much time, if any, to spend working on a project that wasn't relevant to course tests. These poor attitudes can be recognized by students and ultimately also acquired by students. Another example demonstrating a poor faculty attitude occurred when some faculty members requested that the word "ILAP" not be mentioned in the classroom, assuming the students would have a bad attitude having heard about the projects from previous classes. On the other hand, a positive faculty attitude, manifested by a faculty member who is enjoying and/or otherwise supportive of an ILAP, can also be transmitted to students.

\section{What can (and will) go wrong with the STEM faculty?}

We have found that close communication between the mathematics and the other departments is extremely important for the development of ILAPs, and for the coordination of pedagogic content. In the typical institution, where multiple professors are teaching multiple sections of calculus and the other STEM courses, any discussion of ILAPs can often be construed as "additional material". There is an institutional inertia in which the "status quo" reigns supreme. There is a real barrier to coordination and communication of the ideas that common ILAP projects can be utilized as needed, and do not need to be considered as "add-ons". Also, there may be an unwillingness of some faculty members to admit that they really are uncomfortable with math, or feel insecure regarding their math (or other) abilities. A more limited ILAPs development - for example, between champions in just two departments - could perhaps overcome many of these logistical problems and provide a better "sense of ownership" to the projects.

In this project, miscommunications and different interpretations of what was acceptable were common. One major issue was related to "how applied" an ILAP should be. ILAPs that were designed to include hands-on applications could not be implemented efficiently into the larger calculus classes, and availability of "unique" instrumentation and laboratory space was always an issue for the other STEM courses. The differences in personal teaching styles (for example, being well-prepared in advance versus "doing it at the last minute") were magnified by having co-developers/presenters for each ILAP. The coordination and motivation within our STEM group was often limited to "if this is not my grant, or if I am not being paid, it has nothing to do with me" attitudes. In many cases, finding common times for meetings were difficult. In our projects, there was also some discussion as to which mathematical concepts were important for particular STEM courses. Often, only distinct sub-sets of mathematical topics are presented independently for particular STEM courses. These are often repeated independently of their presentation in the calculus courses. 
Essentially, the relationship between calculus education and other STEM courses is at the center of this discussion. Cross-discipline communication and curriculum timing between the sciences, engineering, and mathematics courses has, to some extent, always been difficult. Each field has unique historical themes and conceptual building blocks on which it is structured. Each field has curricular flows which involve faculty specialties, particular textbook use, and "normalized" educational mile posts. The timing of calculus topics can never be fully coordinated to each STEM course, and, often, the selective use of higher mathematical concepts in particular STEM courses will have some sort of "well, if I could only remember this from freshman year" aspect to it. The "common" STEM ILAP developments are, at least, leading to better communication between the participants in this project. The faculty connections that resulted from our trying to develop common ILAPs were the most productive outcome of this project. This is an intended outcome that strengthened the program.

\section{Software Workshops}

Mathematica and MATLAB workshops were conducted during each of the semesters of the project. Workshops were open to all faculty and students within the College of Engineering and Natural Sciences at TU. The workshops were designed for beginning users of the programs and focused on the fundamental operations and capabilities of the programs. The basic instructional materials were supported by extensive hands-on materials and a number of examples that demonstrated how to apply each program's capabilities to engineering problems. Participants were also directed to additional resources made available by faculty within the College, as well as external resources. The workshops were well-received by all participants, with attendance increasing for each successive offering of the workshops. For the MATLAB workshops, several faculty members have expressed interest in adding additional sessions that target several toolboxes that are in common use within the College.

\section{Acknowledgements}

Funding for this work has been provided by the NSF CCLI Program (Grant \# 0410653).

Project faculty from the TU Department of Mathematical and Computer Sciences are Thomas Cairns, Dale Doty, Donna Farrior, William Hamill, Kevin O'Neil, and Shirley Pomeranz.

Project faculty from TU science and engineering departments include William Potter and Dale Teeters, Dept. of Chemistry and Biochemistry; Peter LoPresti and Douglas Jussaume, Dept. of Electrical Engineering; Bryan Tapp, Dept. of Geosciences; Steve Tipton, Dept. of Mechanical Engineering; and Jerome McCoy, Dept. of Physics and Engineering Physics.

\section{Bibliography}

${ }^{1}$ D.C. Arney, editor, Interdisciplinary Lively Application Projects, MAA, 1997.

${ }^{2}$ Felder, Richard M. and Brent, Rebecca, “The intellectual development of science and engineering students - 
Part 2: Teaching to promote growth", Journal of Engineering Education, Oct. 2004, pp. 279-291.

${ }^{3}$ http://www.projectintermath.org, Project INTERMATH.

${ }^{4}$ Wanakat, Phillip and Oreovicz, Frank, "Starting with square one”, ASEE PRISM, November 2005, p. 46.

${ }^{5}$ Holmes, Mark and Spilker, Robert, "Linking undergraduate mathematics education with engineering", International Journal of Engineering Education (IJEE), to appear 2006.

${ }^{6}$ Farrior, Donna; Keiser, Leslie; Kessler, Michael; LoPresti, Peter; McCoy, Jerry; Pomeranz, Shirley; Potter, William; "Enhancing interdisciplinary interactions in the College of Engineering and Natural Sciences: Year 1", 2005 ASEE Conference Proceedings, Portland, OR, June 2005.

${ }^{7}$ Hughes-Hallett, Gleason, McCallum et al., Calculus, Third Edition, John Wiley \& Sons, Inc., 2002.

${ }^{8}$ Selco, Jodye and Beery, Janet, ILAP: "Saving a drug poisoning victim”, University of Redlands, Redlands, CA. 